\title{
ESTUDOS SOCIAIS DA INFÂNCIA NA UNB: apontamentos a partir da produção acadêmica
}

\author{
Monique Aparecida Voltarelli
}

\section{Resumo}

Este artigo é resultado de parte de um projeto de pesquisa sobre os Estudos da Infância nas produções da Universidade de Brasília, que buscou investigar as produções acadêmicas nos Programas de PósGraduação em Ciências Humanas desta universidade a fim de localizar indicativos sobre o campo dos Estudos Sociais da Infância. O texto apresentado refere-se aos dados do Programa de Pós-Graduação em Educação, o qual apresentou maior aproximação e diálogo com o campo da educação infantil. A pesquisa, de cunho bibliográfico e exploratório, utilizou o recorte temporal de 2014 a 2018 e se baseou no novo paradigma da infância, proposto por James e Prout (1990). Verificou-se a presença de alguns elementos do paradigma nos trabalhos analisados, bem como a utilização dos aportes metodológicos para a realização de pesquisas com crianças. Entretanto pode-se dizer que de modo geral ainda é tímida a fundamentação teórica a partir da sociologia da infância nas temáticas investigadas, o que demonstra que as crianças ainda são pouco estudadas e abordadas enquanto sujeitos de estudo por direito próprio e que a infância demonstrou ser compreendida pela perspectiva desenvolvimentista.

Palavras-chave: sociologia da infância; estudos sociais da infância; pesquisa acadêmica; Universidade de Brasília

\section{CHILDHOOD STUDIES AT UNB:} notes from academic production

\begin{abstract}
This article is part of the research project results about Childhood Studies on the productions of University of Brasília, which sought to investigate the academic papers submmited to Postgraduate Programs in Human Sciences of the previously mentioned university to locate indicatives about the field of Childhood Studies. The text presented refers to the data from the Postgraduate Program in Education, which shows superior approximation and dialogue with the field of Early Childhood Education.The bibliographic and exploratory research used the time frame from 2014 to 2018 and was based on the new childhood paradigm, proposed by James and Prout (1990).It was verified the presence of some elements of the paradigm in the analyzed works, as well as the use of methodological contributions for conducting research with children.However, it could be said that, in general, the theoretical approaches of the Sociology of Childhood are still limited, which demonstrates that children are modestly studied and understood at rest as subjects of study in their own right and that childhood has proved to be understood by the developmentalist perspective.
\end{abstract}

Keywords: sociology of childhood; childhood studies; academic research; University of Brasilia. 


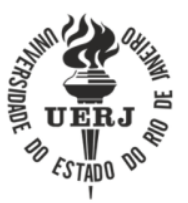

DOI: $10.12957 /$ teias.2022.53019

\section{ESTUDIOS SOCIALES DE LA INFANCIA EN UNB: notas desde la producción académica}

\section{Resumen}

Este artículo es resultado de parte de un proyecto de investigación sobre los Estudios de la Infancia en las producciones de la Universidad de Brasilia, que se ocupó de investigar las producciones académicas en los Programas de Posgrado en Ciencias Humanas de esta universidad, de manera a localizar indicaciones sobre el campo de los Estudios Sociales de la Infancia. El texto presentado se refiere a los datos del Programa de Posgrado en Educación, que presentó una relación más cercana y un diálogo con el campo de la Educación Infantil. La investigación, bibliográfica y exploratoria, utilizó el marco temporal de 2014 a 2018 y se basó en el nuevo paradigma infantil, propuesto por James y Prout (1990). Se verificó la presencia de algunos elementos del paradigma en las publicaciones analizadas, así como el uso de aportes metodológicos para realizar investigaciones con los niños y niñas. Sin embargo, se puede decir que, en general, la base teórica de la sociología de la infancia en los temas investigados sigue siendo restricta, lo que demuestra que los niños y niñas todavía son poco estudiados y entendidos como sujetos de estudio por derecho propio y que la infancia demostró ser comprendida por la perspectiva del desarrollo.

Palabras clave: sociología de la infancia; estudios sociales de la infancia; investigación académica; Universidad de Brasilia.

\section{INTRODUÇÃO}

Os Estudos Sociais da Infância têm se constituído como um campo interdisciplinar, para compreender a complexidade da infância enquanto fenômeno social, que compartilha o entendimento das crianças como atores com significativa participação na construção da história e da cultura, a visão da infância como construção social e, também, como categoria geracional na estrutura social. Este campo, ainda recente e em desenvolvimento no Brasil, tem evidenciado o interesse de pesquisadores em debruçar esforços para realização de pesquisas com as crianças, bem como a compreensão dos elementos que compõem suas vidas, o que constitui uma importante mudança perante as tradicionais abordagens sobre esse grupo social, ou diante da quase inexistência de produções. Tendo em vista que as publicações acadêmicas, tais como dissertações e teses, são meios de produzir e divulgar o conhecimento desenvolvido pelos programas de pós-graduação, além de fornecem indicativos sobre a presença de determinados campos científicos nas universidades, o presente estudo é fruto de uma pesquisa em desenvolvimento, que está mapeando as produções acadêmicas sobre as crianças e a infância dos departamentos de Pós-Graduação em Ciências Sociais e Humanas da Universidade de Brasília. Ademais busca verificar a presença do campo dos Estudos Sociais da Infância nas produções, bem como localizar as crianças e a infância nas produções científicas desta instituição. Para o presente trabalho será apresentado os dados encontrados no Programa de Pós-Graduação em Educação, o qual se verificou uma estreita relação das produções do campo com a área da educação infantil.

Cabe mencionar que o interesse por estudar e investigar a infância e as crianças por si próprias, ainda é recente, de acordo com Sarmento (2007), o campo da Sociologia da Infância surge no final dos anos 80 apresentando uma nova abordagem para estudá-la no contexto social, orientada pelo novo paradigma da infância proposto por James e Prout (1990). Rompendo com visões tradicionais das teorias da socialização e com a concepção universalista do desenvolvimento infantil, o campo da Sociologia da Infância busca trazer visibilidade social e 
científica para as crianças e a infância, considerando-as como atores sociais e a infância enquanto categoria da estrutura social.

De acordo com Nascimento (2016), essa nova concepção de infância se forma a partir de três movimentos durante a segunda metade do século $\mathrm{XX}$, os quais contribuíram para compreensão das crianças como sujeitos de direitos e atores sociais. O primeiro movimento refere-se à legislação internacional e nacional (Constituição Federal de 1988; Convenção dos Direitos das Crianças, 1989; Estatuto da Criança e do Adolescente, 1990; Lei de Diretrizes e Bases da Educação Nacional, 1996) que institui os direitos das crianças e as reconhece como sujeitos; o segundo relaciona-se a repercussão da Pedagogia das Relações ${ }^{1}$ praticadas e difundidas pelas instituições de educação infantil do norte da Itália, (MALAGUZZI, 1999; RINALDI, 1999, 2007); e o terceiro envolve a constituição do campo científico da Sociologia da Infância em países da Europa e dos Estados Unidos (CORSARO, 1979; JENKS, 1982; QVORTRUP, 1987).

A infância, enquanto fenômeno complexo demonstra a necessidade de diálogo entre diferentes campos de conhecimento para realização de estudos e pesquisas, a fim de compreendêla situada de acordo com o contexto em que as crianças estão inseridas. Para Sarmento (2008, p.32) a sociologia da infância "propôs-se a colocar a infância no centro da reflexão das Ciências Sociais" sendo que ela pode ser compreendida como "um componente estruturante do campo interdisciplinar dos Estudos da Infância que está em plena constituição" (p.33, grifo no original). De acordo com Qvortrup, Corsaro e Honig (2009) este campo mais amplo foi primeiramente composto pela Sociologia e pela Antropologia, que tiveram dificuldade em utilizar conceitos e métodos investigativos de cada área para pesquisar as crianças e a infância, convocando diálogo com outras áreas do conhecimento, para ampliar os aportes teóricos e metodológicos acerca da infância.

Dentre as contribuições dos Estudos Sociais da Infância estão as compreensões sobre os direitos das crianças, de forma a ressaltar a capacidade de agência e participação infantil nos diversos espaços sociais, e em especial nas instituições escolares, por serem consideradas e legitimadas pelos adultos enquanto ambientes permitido às crianças frequentarem. Além disso, ressalta-se que as contribuições da Sociologia da Infância e dos Estudos Sociais da Infância ampliam a visibilidade social e científica das crianças pequenas, por um lado, e promovem uma reconfiguração da educação infantil, apresentando outros modos de compreender a infância, a socialização, as relações intergeracionais, por outro (NASCIMENTO, 2016).

De acordo com o sociólogo alemão Honig (2009) este campo, em pouco tempo, se tornou reconhecido enquanto um campo influente na comunidade científica pelas discussões realizadas acerca das crianças. Difundido em diferentes países de diversos continentes, o campo da Sociologia da Infância foi foco de publicação na CurrentSociology em 2010. No volume 58 deste periódico foi apresentado um balanço da situação do campo, para além dos países europeus, o

1Esta pedagogia centraliza-se nas relações que se estabelecem entre a criança e os saberes, nos tempos e espaços, no exercício da escuta, observação, e documentação pedagógica do trabalho realizado nas instituições como elementos essenciais para o processo educativo, valorizando o processo de pesquisa protagonizado pela criança, a arte e a criatividade. O pedagogo e educador italiano, Loris Malaguzzi, foi o criador da pedagogia desenvolvida em Reggio Emília, sendo que suas ideias repercutem até o presente momento, destacando o trabalho educativo como referência internacional para a educação infantil. Para saber mais ver: EDWARDS, Carolyn; GANDINI, Lella; FORMAN, George. As cem linguagens da criança. Porto Alegre: Artes Médicas, 1999. RINALDI, Carla. Diálogos com Reggio Emilia: escutar, investigar e aprender - São Paulo: Paz e Terra, 2012. 
qual tinha o objetivo de identificar a presença da sociologia da infância nos países Reino Unido, Finlândia, França, Alemanha, Itália, Holanda e Romênia, na Europa, Estados Unidos e Austrália. Autoras como Montandon (2001), Sirota (2001), Gaitán Muñoz (2006), Ferreira e Rocha (2015) também realizaram estudos apresentando balanços das produções nas línguas inglesa, francesa e dos trabalhos realizados na Espanha e Portugal (VOLTARELLI, 2017).

Ao compreender a infância enquanto objeto próprio de estudo, Pinto e Sarmento (1997) pontuam a necessidade de mobilizar o conhecimento por meio de diversas disciplinas, a fim de que se possa compreender os diversos fatores que perpassam a vida das crianças e que configuram modos distintos de infância. Entretanto estudar as crianças a partir de si próprias tem demonstrado um primeiro passo de uma longa trajetória de pesquisas, que ainda precisa ser desenvolvida, para que se reconfigure conceitualmente as crianças e a infância no âmbito científico e social, conforme posto por James e Prout (1990). Os estudos no campo, portanto, têm como pressuposto que as crianças são atores sociais, sujeitos de direitos, e demandam pela reflexão teórica e metodológica a fim de ampliar as possibilidades investigativas que considerem as especificidades e particularidades das crianças pequenas, além de considerar os elementos éticos na realização de pesquisas com as crianças.

Segundo a antropóloga brasileira, Clarisse Cohn (2005), os estudos da infância e as investigações sobre as crianças são complexos e de difícil compreensão, assim como as relações que estabelecem desde a perspectiva social e individual. Considerar que existem diversas maneiras de ser criança, de viver a infância, coloca-se como um desafio para os pesquisadores que tem buscado compreendê-las a partir de suas perspectivas, além disso, é importante dizer, que desconstruir o imaginário acerca de uma infância ideal, universal e normativa, que fez com que as crianças estivessem em uma condição de vir a ser cidadão, enquanto adultos, tem demandado revisitar as construções acerca da infância e as variações deste conceito em cada época histórica, levando em consideração o contexto geográfico e social (KEHILY, 2015).

Neste sentido, cabe mencionar as contribuições da socióloga francesa, Sirota (2012, p.6) quando aponta a necessidade de

[...] revisitar a socialização contemporânea, toda a desconstrução da problemática da socialização; [...] considerar a infância como um ser no presente; de tomar em conta as restrições estruturais que pesam sobre as crianças, considerando como membros e parte completa da sociedade, a partir de um ponto de vista que se embasa sobre a interseção da relação social dentro das quais se insere a vida cotidiana das crianças; de utilizar os instrumentos ordinários das disciplinas das ciências sociais.

Castro e Kosminky publicaram em 2010 um artigo apontando as relações dos estudos sobre as crianças e a infância no Brasil, os quais estavam atrelados aos problemas sociais, afirmando que, somente após a aprovação da Constituição Federal (1988) e do Estatuto da Criança e do Adolescente (1990), as crianças passam a ser reconhecidas como sujeitos de direitos, o que as transforma em foco da agenda política e as tornam visíveis na pesquisa acadêmica. As autoras apresentam também um balanço da produção acadêmica brasileira e, ao final do artigo, referem à Sociologia da Infância como campo de estudos em construção.

Estudos no Brasil (ABRAMOWICZ; OLIVEIRA, 2010; CRUZ, 2008; CASTRO, 1998; DELGADO; MÜLLER, 2005; FARIA, 2007, 2008; FARIA, FINCO, 2011; KAUFMAN; RIZZINI, 2002; GOUVEA; SARMENTO, 2008; MARCHI, 2007; QUINTEIRO, 2000; entre outros) tem demonstrado a existência de grupos de pesquisa, bem como pesquisadores isolados, 
que tem desenvolvido investigações a partir da perspectiva da Sociologia da Infância, contribuindo para o desenvolvimento do campo, bem como permitindo compreender que a maior predominância de estudos e pesquisas são oriundos dos programas de Pós-Graduação em Educação (NASCIMENTO et al, 2013; NASCIMENTO 2016).

Quinteiro (2002), por sua vez, em texto sobre a emergência de uma Sociologia da Infância no Brasil, demonstra a necessidade de ampliação de investigações e estudos no campo das Ciências Sociais e Humanas a fim de que se possa compreender a evolução do objeto e do olhar sobre a infância. Segundo a autora,as produções podem ser consideradas como "faróis de análises" que permitem observar, ouvir e analisar as vozes das crianças, ademais de possibilitar o aprofundamento teórico sobre a infância e as crianças nos diversos campos do conhecimento.

Levar em consideração as vozes das crianças nas produções científicas requer rever as compreensões acerca da infância, bem como refletir sobre métodos sociológicos de pesquisa que permitam escutar as crianças em suas diversas formas de expressão, considerando suas particularidades e singularidades. De acordo com Saporiti (1994, p.190) os esforços para trazer visibilidade para as crianças destacam a necessidade de trabalhar com estatísticas, indicações demográficas, sociais e econômicas nas quais as crianças estejam inseridas, e que nem sempre são retratadas, centralizando-as nas investigações científicas enquanto unidade de observação e a infância como unidade de análises.

As crianças historicamente ocuparam lugar periférico na história e na sociedade em geral, conforme ressaltam Abramowicz e Oliveira (2010) o que tem dificultado estudiosos em localizar material produzido pelas próprias crianças e compreender a infância a partir de suas perspectivas. Permitir que as crianças sejam protagonistas, ocupando seu lugar na história e no presente, além de avançar nos estudos acerca dos processos de socialização e produção cultural das crianças, são aspectos, que segundo as autoras, devem ser considerados no desenvolvimento do campo no Brasil.

Assim, no intuito de contribuir para o desenvolvimento do campo dos Estudos Sociais da Infância, o presente texto traz indicativos da pesquisa realizada no Programas de Pós-Graduação em Educação da Universidade de Brasília, a fim de demonstrar se o departamento tem se apropriado (ou não) deste campo científico e identificar se existem esforços nesta universidade de reconceitulizar as crianças na sociedade, bem como superar a visão desenvolvimentista atrelada à infância, o que tem impossibilitado conceber as crianças enquanto cidadãs no presente.

A pesquisa

O presente artigo é fruto de um projeto de pesquisa, financiado pelo Decanato de Pesquisa e Inovação da Universidade de Brasília, que visa identificar a presença do campo dos Estudos Sociais da Infância nas produções acadêmicas dos Programas de Pós-Graduação em Ciências Humanas na Universidade de Brasília. Para este texto buscou-se apresentar os dados da investigação realizada no Programa de Pós-Graduação em Educação, a qual foi desenvolvida por meio de uma pesquisa exploratória no repositório da CAPES, e também repositório institucional da Universidade de Brasília (UnB), a fim de verificar se as teses e dissertações dialogam com o campo dos Estudos Sociais da Infância. 
O levantamento de dados ocorreu em 2019 e considerou: a) o levantamento e localização das produções do Programa de Pós-Graduação em Educação no período de 2014 a $2018^{2}$ no repositório da CAPES e da UnB utilizando os descritores: infância, infâncias, criança, crianças, sociologia da infância e estudos sociais da infância; b) inclusão dos trabalhos localizados a partir dos descritores e do recorte temporal, bem como a organização dos dados em planilhas do Excel; c) seleção prévia das produções por meio da leitura de título, resumo e palavras-chave das teses e dissertações encontradas; d) leitura na integra das publicações selecionadas e inclusão de trabalhos que apresentassem relação com o paradigma da infância proposto por James e Prout (1990) análise dos textos incluídos no corpus da pesquisa.

James e Prout publicaram em 1990 a proposta de um novo paradigma para orientar os estudos das crianças e da infância, instituindo-se como um marco para o campo da Sociologia da Infância ao reconceitualizar as crianças e a infância, de forma a tornar visível as perspectivas das crianças no campo científico, considerando-as como agentes sociais, que devem ser estudadas em seu próprio direito. Para este fim os autores propõem alguns princípios:(1) a infância é uma construção social, que varia de acordo com a cultura, apesar de ser um componente estrutural específico em todas as sociedades conhecidas; (2) a infância, como variável de análise social, não pode ser totalmente desvinculada de outras variáveis, como classe, gênero e etnia; (3) relações sociais e culturas de crianças merecem ser estudadas por si mesmas; (4) crianças são e devem ser vistas como atores envolvidos ativamente na construção de suas próprias vidas, na vida daqueles que as cercam e na sociedade em que vivem; (5) a etnografia é uma metodologia a ser priorizada, pois permite à criança voz mais direta na produção de dados sociológicos; e (6) a infância é um fenômeno em relação, para o qual a dupla hermenêutica das ciências sociais está fortemente presente, já que um novo paradigma de estudo traz repercussões para a reconstrução da infância na sociedade (JAMES; PROUT, 1990, p. 8-9).

A pesquisa das produções acadêmicas resultou na localização de 478 trabalhos relacionados à infância pelo Programa de Pós-Graduação em Educação da UnB publicadas entre 2014 e 2018. Destes 102 foram incluídas após a leitura dos títulos, resumos e palavras-chave, sendo que após a leitura na integra dos textos restaram 37 produções que foram selecionados para compor o corpus de análise da investigação por apresentarem indicativos do campo dos Estudos Sociais da Infância. Destas produções 25 são frutos de pesquisa de mestrado e 12 de doutorado, os quais foram divididos em cinco categorias de análise (por meio da aproximação dos temas), a saber: a) educação infantil; b) infância e diversidade; c) institucionalização da infância; d) infância no campo; e) cidadania.

As produções categorizadas como educação infantil, compõem $29 \%$ dos trabalhos do Programa de Pós-Graduação de Educação da UnB, no período de 2014 a 2017, demonstrando maior relação com o campo dos Estudos Sociais da Infância. A partir dos trabalhos foi possível identificar como as crianças e a infância foram compreendidas e conceitualizadas nas produções, os aportes metodológicos utilizados nas pesquisas com crianças, bem como as relações estabelecidas entre o campo da Educação Infantil com os Estudos Sociais da Infância.

A categoria de infância e diversidade compõe 22\% das publicações e compreende 2014 a 2018 abordando trabalhos que compreendem as infâncias plurais e destacam a importância das

\footnotetext{
${ }^{2}$ A pesquisa iniciou-se em 2019 e buscou localizar as produções dos últimos cinco anos nos Programas de PósGraduação em Ciências Humanas e Sociais da Universidade de Brasília a fim de identificar a presença e/ou diálogo com o campo dos estudos sociais da infância nas publicações acadêmicas em nível de mestrado e doutorado.
} 
crianças para manter as tradições culturais por gerações. Apesar de ser a categoria que menos dialogou com os referenciais do campo dos Estudos Sociais da Infância, foi possível notar a presença do paradigma nas publicações.

Em relação à categoria institucionalização da infância, a qual representa $19 \%$ das publicações no departamento de Educação, demonstrou fundamentação e diálogo com o campo dos Estudos Sociais da Infância, principalmente ao trabalhar com os conceitos de menoridade, direito das crianças e bem-estar social da infância. Além disso, verificou-se diálogo com outras áreas do conhecimento para ampliar o entendimento das temáticas estudadas, o que demonstra a necessidade de desenvolver estudos interdisciplinares para compreender a complexidade do fenômeno infância.

No que se refere à categoria infância no campo, que compreende quase que $17 \%$ das teses e dissertações publicadas neste período, foi possível identificar a presença de autores consagrados no campo, tais como Àries (1986); Corsaro (2011); Prout (2010); Sarmento (2004, 2008); Qvortrup (2011), que contribuíram para teorização das publicações, demonstrando a necessidade de trazer visibilidade para as questões que perpassam a vida das crianças do campo, ressaltando a singularidade e especificidade da infância que demanda por olhares educativos atentos a realidade deste contexto em que vivem.

Cidadania, por fim, constitui a última categoria de análise, a qual compreende $13 \%$ dos trabalhos que contemplam temáticas socioambientais no espaço urbano, tendo em vista projetos educativos que envolvam práticas de cidadania com as crianças. Nesta categoria encontram-se apenas teses, que não consideram necessariamente as crianças como ponto de partida para realização dos trabalhos, mas que demonstram cuidado e atenção na escolha de instrumentos de coleta de dados para realização de pesquisa, que possibilitassem abranger os pontos de vista das crianças.

\section{Indicativos e aproximações do campo com as pesquisas da educação}

Dentre o período compreendido pela pesquisa, pode-se afirmar que as produções referenciaram autores do campo, principalmente entre os anos de 2014 e 2016, sendo que até 2015 nota-se grande fundamentação a partir do paradigma proposto por James e Prout (1990). A partir de 2016, houve uma queda das citações dos autores do campo, apesar de manter frequente até 2018 as fundamentações teóricas, conforme pode-se visualizar no gráfico abaixo:

Gráfico 1- Fundamentação e referencial teórico

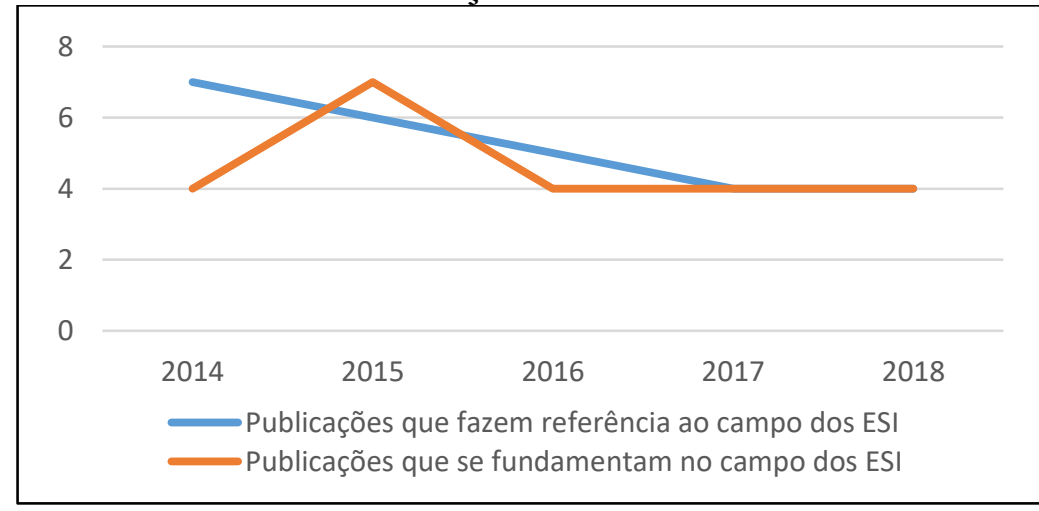

Fonte: elaboração própria, 2020. 
Destaca-se que dentre os autores mais citados estão: Willian Corsaro; Phelipe Àries Manuel Sarmento; Jens Qvortrup; Fernanda Müller; Clarisse Cohn; Alan Prout; Virginia Morrow; Florestan Fernandes; Allison James; Regine Sirotá; Berry Mayall; Priscilla Alderson; Cléopâtre Montandon; Lourdes Gaitán Muñoz; Samantha Punch; Pia Christensen e Catarina Tómaz. Esta variedade de autores, que demarcam a estruturação do campo da Sociologia da Infância e/ou contribuem para o desenvolvimento do mesmo, demonstra a presença e diálogo com o referencial, entretanto cabe mencionar que os trabalhos categorizados como educação infantil pode-se notar maior aprofundamento teórico e metodológico nas pesquisas realizadas neste período.

Outro indicativo em relação às publicações refere-se ao financiamento da pesquisa, sendo que apenas em 2014 e 2015 as teses e dissertações tiveram suas pesquisas financiadas pela CAPES e CNPQ, sendo que após este período em nenhuma produção foi verificado a realização de pesquisas com bolsas, o que indica uma queda de investimentos na realização de pesquisas em ciências humanas, e principalmente nos temas relacionados às crianças e a infância.

Em relação aos aportes metodológicos, a análise das produções indica a predominância de pesquisas qualitativas, com a priorização de estudos de caso, seguidas de etnografia ou com inspirações etnográficas, pesquisas exploratórias, pesquisa-ação, pesquisa de campo e documentais. Tendo como principais instrumentos de coleta de dados a observação participante, diário de campo, entrevistas, roda de conversas, uso de desenhos, jogos e brincadeiras; fotografias e filmagens, bem como oficinas, dinâmicas, e grupos focais para realização de pesquisa com as crianças.

A pesquisa com as crianças foi mais frequente nas publicações categorizadas como educação infantil, sendo que esta categoria se destaca também na quantidade de publicações que tiveram a preocupação de submeter o trabalho em comitê de ética e obter autorização oral das crianças participantes das pesquisas. Entretanto os demais autores demonstraram cuidados na realização de pesquisa com crianças no sentido de obter a assinatura de termo de consentimento dos pais, e uso de nomes fictícios, porém a documentação ou indicativos de que foram submetidos a comitês de ética não foram encontrados. Outro fator que cabe destacar refere-se ao convite às crianças para realização das pesquisas, e neste sentido, apenas nos trabalhos da educação infantil que houve momentos descritos pelos autores para explicar para as crianças do que se tratava a pesquisa, para então fazer o convite para a participação.

A escuta das crianças foi ressaltada nas publicações categorizadas como educação infantil, em rodas de conversas, por meio de contação de histórias e uso de desenhos durante a realização da investigação; já nas publicações referentes a institucionalização da infância identifica-se o uso de brincadeiras, jogos e diversas atividades lúdicas para promover esta escuta, demonstrando diversidade de instrumentos metodológicos para envolver as crianças; quanto a categoria infância e diversidade as crianças foram consultadas, na maioria dos trabalhos, apenas para obter informações especificas que envolviam os objetivos de cada pesquisa; as publicações categorizadas como infância do campo não tinham como foco principal a pesquisa com crianças, mas estas contribuíram com as investigações, envolvendo a participação de crianças maiores em entrevistas e menores nas brincadeiras, jogos e oficinas; e por fim, a categoria cidadania as crianças foram envolvidas em oficinas pedagógicas, atividades lúdicas, por meio de desenhos, métodos visuais e conversas que fizeram uso de fotografias a fim de buscar a percepção das crianças sobre o mesmo tema em momentos distintos da pesquisa. Além destes, cabe mencionar 
que diversos trabalhos optaram pela percepção dos adultos sobre as crianças, ou analisaram concepções de crianças a partir de documentos e/ou memórias da infância dos adultos.

As dissertações de mestrado predominaram em relação às teses de doutorado, no que tange a pesquisa sobre a infância, sendo que em 2015 nota-se maior quantidade de publicações no Programa de Pós-Graduação em Educação, com uma significativa diminuição no interesse sobre as temáticas em 2016, conforme se pode visualizar no gráfico abaixo:

Gráfico 2- Tipos de produções

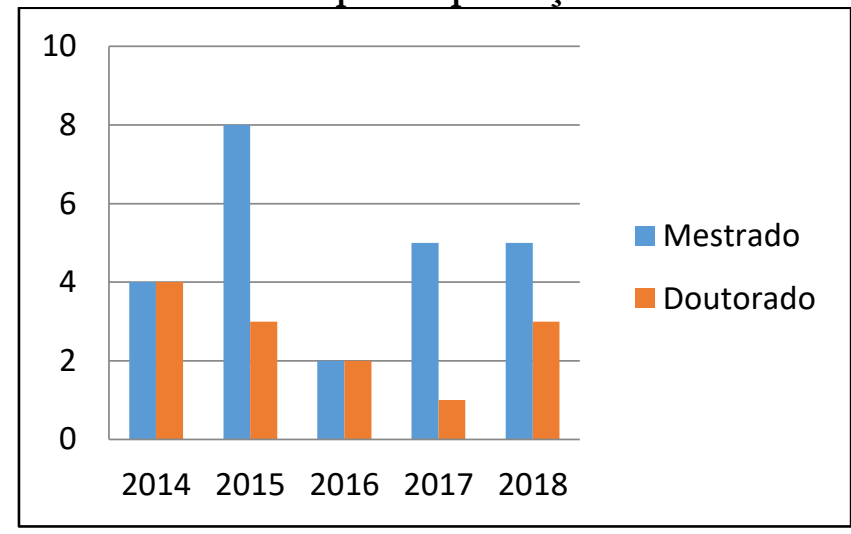

Fonte: elaboração própria, 2020.

No que se refere às crianças investigadas, de acordo com o gráfico abaixo, pode-se dizer que as crianças pequenas e as crianças enquanto alunas foram predominantes nas pesquisas, $\mathrm{O}$ que indica que grande parte das investigações foirealizada em instituições educativas e escolares, com destaque para os anos de 2015, 2016 e 2018. Porém, cabe mencionar que as crianças foram investigadas para além dos muros escolares, em menor proporção, sendo consideradas na relação com a cidade, com o campo, em instituições de acolhimento institucional, abrigos, em situações de vulnerabilidade, em ocupações e assentamentos, bem como em comunidades indígenas, quilombolas e ciganas.

Gráfico 3- Crianças investigadas

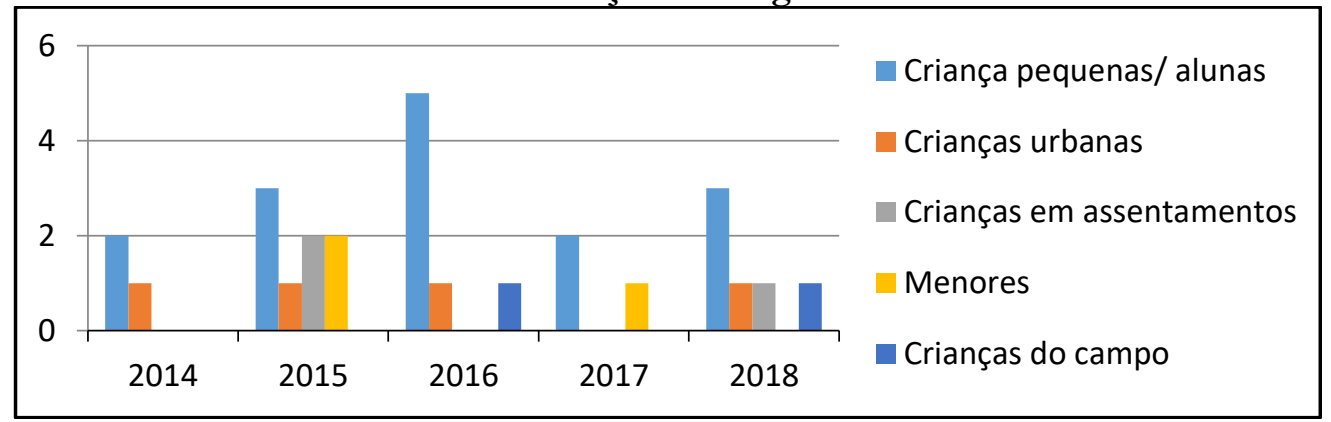

Fonte: elaboração própria, 2020.

Em relação à compreensão da infância, muitos trabalhos apresentaram a perspectiva desenvolvimentista, colocando as crianças em posição de vir a ser, entretanto a infância como construção social foi abordada na maior parte dos trabalhos, o que não se pode dizer da infância compreendida enquanto categoria geracional na estrutura social, uma vez que apenas nas 
produções categorizadas como educação infantil e infância e diversidade, essa conceitualização aparece, de forma a destacar a importância das crianças para a manutenção das tradições culturais e para apontar a necessidade de pensar as relações estabelecidas entre adultos e crianças nas instituições educativas.

Ressalta-se ainda que as crianças foram abordadas como produtoras de cultura, atores sociais e enquanto sujeitos de direitos. A compreensão das crianças enquanto produtora de cultura foi significativamente utilizada nas publicações, ainda que não aparecesse na teorização, mas foi identificada nas falas dos entrevistados, nas citações, ou nas descrições de situações demonstrando a importância do papel social das crianças para a cultura. Nas publicações categorizadas como institucionalização da infância, foi possível identificar a abordagem da cidadania, bem-estar social e direito das crianças nas instituições de acolhimento e instituições sócios educativas, sendo que nestes trabalhos foi possível identificar o uso do conceito de protagonismo infantil, o qual não foi percebido nas demais categorias. Nas publicações da categoria infância do campo, as crianças enquanto sujeitos de direitos foram abordadas para ressaltar a necessidade de garantir educação para criança filhas de famílias envolvidas em disputas territoriais, que lutam por assentamentos ou associados a movimentos sociais por terem seus direitos negados.

No que tange ao alcance do paradigma proposto por James e Prout (1990, p. 8-9) as produções indicam forte presença do primeiro e segundo paradigma que refere-se à compreensão da infância enquanto construção social e da infância enquanto variável de análise que não pode ser separada de outras tais como classe social, gênero e etnia. $O$ paradigma referente às relações das crianças com suas culturas foram abordadas principalmente nos trabalhos categorizados como educação infantil e infância e diversidade; o quarto paradigma que dispõe sobre a necessidade das crianças serem estudadas como atores sociais na construção de sua vida social e da vida das pessoas que as rodeiam pode ser percebida principalmente nas categorias infância institucionalizada e cidadania; o quinto e o sexto paradigma foram identificados em apenas três publicações, uma vez que não houve um estudo etnográfico com as crianças, mas com inspirações etnográficas com adultos e crianças; e raramente identificou-se nas teses e dissertações o entendimento da infância enquanto fenômeno no qual se encontra a dupla hermenêutica das ciências sociais evidenciadas por Giddens, sendo que apenas estes trabalhos explicitaram os esforços no processo de reconstruir a criança e a sociedade.

E por fim, aponta-se que o tempo de realização de pesquisa com as crianças não foi mencionado, assim como a idade das crianças só pode ser percebida pela associação das séries escolares, mas as que foram investigadas foras das instituições foram caracterizadas apenas como menores, bebês, crianças pequenas ou crianças maiores. O conceito de socialização também foi fortemente utilizado nas teses e dissertações, mas verificou-se que o viés adultocêntrico ainda perpetuam as produções, havendo poucos questionamentos em relação às relações de poder estabelecidas entre adultos e crianças.

\section{CONSIDERAÇÕES FINAIS}

As teses e dissertações analisadas na pesquisa permitem concluir a existência de indicativos do campo dos Estudos Sociais da Infância, mas especificamente da Sociologia da Infância em termos metodológicos, no âmbito teórico nota-se divergências de autores que ora se 
apoiam na Psicologia do desenvolvimento e ora utilizam conceitos do campo da Sociologia da Infância para abordar as crianças como produtoras de culturas e sujeitos de direitos.

Apesar dos textos estudados demonstrarem diálogos com o paradigma proposto por James e Prout (1990) nota-se que a apropriação do campo ainda é rasa, sendo que apenas a categoria da educação infantil demonstrou maior coerência entre o aporte teórico e metodológico da Sociologia da Infância. Porém não se pode afirmar que o campo é utilizado para compreender e desenvolver pesquisas acerca da educação infantil no departamento, pois diversos trabalhos que tratavam desta temática, no período proposto para esta investigação, priorizaram a teoria histórico-cultural na realização das pesquisas, as quais foram desconsideradas para o corpus de análise, mas que indicam que a Psicologia ainda é o principal campo utilizado para estudar as crianças pequenas neste programa de pós-graduação.

Considerar a participação das crianças nas pesquisas, respeitando os procedimentos éticos, trazendo suas falas e perspectivas de maneira que extrapolem a ilustração de suas falas nos textos, elaborados pelos adultos, que recortam e selecionam as falas das crianças nas pesquisas, descontextualizando suas perspectivas com a temática investigado. Estes elementos indicam ainda que rever posturas adultocêntricas na elaboração do texto final para divulgação do conhecimento científico é urgente e necessária.

O protagonismo das crianças, no âmbito científico, tem despertado a atenção de diversos investigadores da infância, e tem demandado o questionamento de formatos que as pesquisas têm sido feitas, bem como a maneira como elas tem sido retratadas na investigação, carecendo de atitudes e abertura de espaços que permitam que as crianças ocupem não apenas o cenário investigativo e científico, mas também social e cultural.

Neste aspecto ressaltam-se outras problemáticas envolvidas, pois a necessidade de reformular as compreensões acerca da infância e das crianças requer outros modos de pensar a educação das crianças pequenas, o que convida adultos, pesquisadores e professores e demais profissionais envolvidos na educação a repensar as relações estabelecidas com elas, o modo que as escutam (e quando escutam), levando em consideração suas múltiplas linguagens e formas de expressão. Por mais que as intenções sejam boas para essa reconstrução, precisam ser transformadas em ações que tragam sentidos de pertencimento às crianças nos diversos ambientes em que estão inseridas, considerando-as concretas e plurais, respeitando a diversidade cultural, religiosa de meninos e meninas que continuam sem ter suas vidas contadas, registradas e problematizadas tanto no cenário científico quanto social.

Trazer visibilidade às crianças por meio das produções científicas é um modo de demonstrar as maneiras que tem se colocado luz em algumas infâncias e não em outras, o que requer desafiar estudiosos e pesquisadores da infância a descobrir tudo que está oculto, e neste aspecto acredita-se que não há ninguém melhor do que as crianças para ajudar a iluminar os caminhos de pesquisas que os adultos ainda não conseguem ver.

\section{REFERÊNCIAS}

ABRAMOWICZ, Anete; OLIVEIRA, Fabiana. A Sociologia da Infância no Brasil: uma área em construção. Educação (UFSM), vol., n.1, p. 39 - 52, 2010. Disponível em: https://periodicos.ufsm.br/reveducacao/article/view/1602 Acesso em: 10 jan. 2020.

ARIÈS, Phelippe. História social da criança e da família. 2. ed. Rio de Janeiro: Editora Guanabara, 1986. 
CASTRO, Lucia Rabelo de; KOSMINSKY, Ethel. Childhood and its Regimes on Visibility in Brazil. An Analysis of the Contribution of the Social Sciences. Current Sociology, v. 58, n. 2, 2010, p. 206-231, mar.

CASTRO, Lucia Rabelo de. Infância e adolescência na cultura do consumo. Rio de Janeiro: NAU, 1998.

COHN, Clarice. Antropologia da Criança. Rio de Janeiro: Zahar, 2005.

CORSARO, Willian. Sociologia da infância. ed. 2. Porto Alegre: Artmed, 2011.

CORSARO, Willian. Young children's conception of status and role. Sociology of Education, v. 2, n.1, p.46-59, jan., 1979.

CRUZ, Silvia Helena Vieira. A criança fala: a escuta de crianças em pesquisas. São Paulo: Cortez, 2008.

DELGADO, Ana Cristina Coll; MÜLLER, Fernanda. Sociologia da infância: pesquisa com crianças. Educação e Sociedade, Campinas, n. 91, v. 26, p. 351-360, 2005. Disponível em: https://www.scielo.br/j/es/a/GdNZMSwhJTXwFJ3RhbfYjpJ/?lang=pt. Acesso em: 18 fev. 2022.

FARIA, Ana Lucia Goulart de; FINCO, Daniela. (orgs.). Sociologia da Infância. Campinas, SP: Autores Associados, 2011.

FARIA, Ana Lucia Goulart de. O Coletivo Infantil em Creches e Pré-Escolas: Falares e Saberes. São Paulo: Cortez, 2007.

FARIA, Ana Lucia Goulart de; MELLO, Suely Amaral. (orgs.) Territórios da Infância: linguagens, tempos e relações para uma pedagogia para as crianças pequenas. Araraquara: Junqueira \& Marin, 2008.

FERREIRA, Manuela; ROCHA, Cristina. A sociologia da infância e os estudos da infância em Portugal (1990-2012): emergência e desenvolvimento. In: REIS, Magali dos; GOMES, Lisandra Ogg. (orgs). Infância: sociologia e sociedade. SP: EdiçõesLevana/ Attar Editorial, 2015, p.191-220.

GAITÁN MUÑOZ, Lourdes. La nueva sociología de la infancia. Aportaciones de una mirada distinta. Política y Sociedad, v.43, n. 1, 2006, p. 9-26. Disponível em: https://revistas.ucm.es/index.php/POSO/article/view/POSO0606130009A. Acesso em $10 \mathrm{de}$ jan. 2020.

GOUVEA, Maria Cristina; SARMENTO, Manuel Jacinto. Estudos da Infância. Petrópolis: Vozes, 2008.

HONIG, Michel-Sebastian. How is the Child constituted in Childhood studies? In: QVORTRUP, Jens; CORSARO, Willian; HONIG, Michel-Sebastian. The Palgrave Handbook of Childhood Studies. Palgrave Macmillan, 2009.

JAMES, Allison; PROUT, Alan. Constructing and reconstructing childhood: Contemporary issues in the Sociological Study of Childhood. London: The Falmer Press, 1990.

JENKS, Cris. (ed). The sociology of childhood: essential readings. London: Batsford, 1982.

KAUFMAN, Natalie Hevener; RIZZINI, Irene. Globalization and children: exploring potentials for enhancing opportunities in the lives of children and youth. New York: Klumer Academic; Plenum, 2002.

KEHILY, Mary Jane. An introduction to childhood studies. London: Open University Press, 2015. 
MALAGUZZI, Loris. Histórias, ideias e filosofia básica. In: EDWARDS, Caroline; GANDINI, Lella; FORMAN, George. As cem linguagens da criança: a abordagem de Reggio Emilia na educação da primeira infância. Porto Alegre: Artmed, 1999.

MARCHI, Rita de Cassia. Os Sentidos (paradoxais) da Infância nas Ciências Sociais: um estudo de Sociologia da Infância crítica sobre a "não-criança" no Brasil. Florianópolis, 2007. Tese (Doutorado em Sociologia Política) - Universidade Federal de Santa Catarina. Programa de PósGraduação em Sociologia Política, Florianópolis, 2007.

MONTANDON, Cleopatre. Sociologia da Infância: balanço dos trabalhos em língua inglesa. Cadernos de Pesquisa, São Paulo, n.112 p. 33-60, mar. 2001. Disponível em: https://www.scielo.br/j/cp/a/sdJPPzYbpq6NBY75YhdNwdr/?lang=pt. Acesso em: 18 fev. 2022.

NASCIMENTO, Maria Letícia Barros Pedroso. (Coord.). Infância e Sociologia da Infância: entre a invisibilidade e a voz. Relatório Científico. São Paulo: FEUSP/ CNPq, 2013.

NASCIMENTO, Maria Letícia Barros Pedroso. Educação infantil e sociologia da infância. Estudo sobre as relações entre a pesquisa em estudos da infância e os contextos nos quais é realizada. 2016. Tese (Livre Docência em Educação infantil) - Faculdade de Educação, Universidade de São Paulo, São Paulo, 2016.

PINTO, Manuel; SARMENTO, Manuel Jacinto. (org.). As crianças: contextos e identidades. Braga: Centro de Estudos da Criança, Universidade do Minho, 1997.

PROUT, Alan. Reconsiderando a nova sociologia da infância. Cad. Pesqui. São Paulo, v. 40, n. 141, p. 729-750, dez., 2010. Disponível em: https://www.scielo.br/j/cp/a/86463c9grYmgkkL6NNV4wxD/abstract/?lang=pt. Acesso em: 18 fev. 2022.

QUINTEIRO, Jucirema. Infância e educação no Brasil: um campo de estudo em construção. In: FARIA, Ana Lucia Goulart de; DEMARTINI, Zeila de Brito Fabri; PRADO, Patrícia Dias. (org.). Por uma cultura da infância: metodologias de pesquisa com crianças. Campinas: Autores Associados, 2002.

QUINTEIRO, Jucirema. Infância e escola: uma relação marcada por preconceitos. 2000. Tese (doutorado) - Faculdade de Educação. Universidade Estadual de Campinas, Campinas.

QVORTRUP, Jens. Introduction of sociology of childhood. International Journal of Sociology, v. 17, n. 3, p. 3-37. Fall, 1987.

QVORTRUP, Jens. Nove teses sobre a "infância como um fenômeno social”. Pro-Posições, v. 22, n. 1, p. 199-211, abr. 2011. Disponível em: https://www.scielo.br/j/pp/a/dLsbP94Nh7DJgfdbxKxkYCs/?lang=pt. Acesso em: 18 fev. 2022.

QVORTRUP, Jens; CORSARO, Willian; HONIG, Michel-Sebastian. The Palgrave Handbook of Childhood Studies. London: Palgrave Macmillan, 2009.

RINALDI, Carla. In dialogue with Reggio Emilia: listening, researching and learning. NY: Routlegde, 2007.

RINALDI, Carla. O currículo emergente e o construtivismo social. In: EDWARDS, Caroline; GANDINI, Lella; FORMAN, George. As cem linguagens da criança: a abordagem de Reggio Emilia na educação da primeira infância. Porto Alegre: Artmed, 1999. 
SAPORITI, Angelo. A Methodology for Making Children Count. In: QVORTRUP, Jens et al. (Ed.). Childhood Matters: Social Theory, Practice and Politics. Aldershot: Avebury, 1994.

SARMENTO, Manuel Jacinto. As culturas da infância nas encruzilhadas da segunda modernidade. In: SARMENTO, Manuel Jacinto; CERISARA Ana Beatriz. Crianças e miúdos: perspectivas sócio-pedagógicas da infância e educação. Porto: Asa, p. 9-34, 2004.

SARMENTO, Manuel Jacinto. Sociologia da Infância: correntes e confluências. In: GOUVEA, Maria Cristina; SARMENTO, Manuel Jacinto (orgs.) Estudos da infância: educação e práticas sociais. Petrópolis: Vozes, 2008, p. 17-39.

SARMENTO, M. J. Visibilidade social e estudo da infância. In: Vasconcellos, Vera Maria Ramos de; SARMENTO, Manuel Jacinto (orgs). Infância (in)visivel. Araraquara, SP: Junqueira \& Marin, 2007.

SIROTA, Regine. Emergência de uma Sociologia da infância: evolução do objeto e do olhar. Cadernos de Pesquisa, São Paulo, n. 112, p. 7-31, mar. 2001. Disponível em: https://www.scielo.br/j/cp/a/X8n4RcnLnhdybsVSwNG5Twv/abstract/?lang=pt. Acesso em: 18 fev. 2022.

SIROTA, Regine. L'enfance au regard des Sciences sociales. AnthropoChildren, n. 1, jan/2012.

VOLTARELLI. Monique Aparecida. Estudos da infância na América do Sul: pesquisa e produção na perspectiva da sociologia da infância. 2017. Tese (Doutorado em Educação) - Faculdade de Educação, Universidade de São Paulo, São Paulo, 2017.

\section{Informações da autora}

Monique Aparecida Voltarelli

Universidade de Brasília

E-mail: moniquevoltarelli@yahoo.com.br

ORCID: https://orcid.org/0000-0003-2605-0930

Link Lattes: http://lattes.cnpq.br/1525508411734718 